\title{
The influence of the cargo weight and its position on the braking characteristics of light commercial vehicles
}

https://doi.org/10.1515/eng-2020-0024

Received Sep 26, 2019; accepted Nov 27, 2019

\begin{abstract}
The influence of the cargo weight loaded on the vehicle and the total gross mass of the vehicle on the braking characteristics is often researched from the road safety reason. However, there is not enough knowledge about the influence of weight and load distribution on the loading area of small trucks or vans on their braking characteristics. This article presents the results of measurements of braking decelerations of the van of N1 category and the braking characteristics of a vehicle loaded with different cargo mass with different cargo locations on the loading area. The impact of the longitudinal cargo position on the loading area on the load of the individual axles and thus on the braking deceleration of the vehicle was investigated. The influence of the height of the center of gravity on the dynamic axle load during braking was also determined. Method of direct vehicle deceleration measurement was used by a decelerometer. There were calculated cargo weight and cargo position influences on the dynamic axle load during braking according to the vehicle deceleration.
\end{abstract}

Keywords: Braking deceleration, light commercial vehicle, axle load, load position, center of gravity height

\section{Introduction}

In general, the ability to brake a vehicle is a very important aspect in terms of road safety [1]. Braking is a dynamic ef-

\footnotetext{
^Corresponding Author: Tomas Skrucany: University of Zilina, Department of Road and Urban Transport, Univerzitna 1, 01026 Zilina, Slovakia; Email: tomas.skrucany@fpedas.uniza.sk Jan Vrabel: University of Zilina, Department of Road and Urban Transport, Univerzitna 1, 01026 Zilina, Slovakia; Email: jan.vrabel@fpedas.uniza.sk

Patrik Kazimir: University of Zilina, Department of Road and Urban Transport, Univerzitna 1, 01026 Zilina, Slovakia;

Email: kazimir2@stud.uniza.sk
}

fect, when changing the speed of the vehicle at the time and at a certain route. It is important that the speed decreases as much as possible in the shortest time and distance [2-4]. As specified in [5] and [6] the decrease in speed over time is defined by the braking deceleration. It is a parameter that describes the "greatness" of braking and is useful for comparing different car types under different conditions [7-10]. It cannot be said about the braking time or stopping distance, which vary significantly due to a initial speed changes from which the vehicle decelerates [11].

The issue of vehicle braking has been described in several publications. For example the authors in literature [12] and [13] discuss that braking deceleration, and therefore braking characteristics are primarily affected by the adhesion between the wheel and the road surface (also influenced by atmospheric conditions), the efficiency of the braking system [14], vehicle gross mass, weight distribution on the loading area [3] and the technical conditions of the vehicle [15]. From the perspective of the vehicle operator only vehicle actual mass and load distribution on the loading area can be changed $[16,17]$.

The vehicle center of gravity is very important during the vehicle braking. The actual position of the gravity center is given by the gravity center of empty vehicle (technical parameter) and by actual mass of load and its position (operation parameter). The actual loaded vehicle center of gravity effects the actual axle loads. The determination of the axle loads (front and rear axle) is given by its longitudinal position within the wheelbase. There are two types of axle load - static and dynamic axle load. The static axle load is acting by non-moving vehicle. We consider the dynamic axle load by vehicle in motion. The difference between these two axle loads is increasing with the actuating vehicle-in-motion accelerations - lateral (side differences of the wheels) and longitudinal (front/rear axle differences) and vertical (overall differences).

It is possible to make a direct measurement of the dynamic axle loads by using special measuring devices. We used another way to determine it - the measurement of static axle load and accelerations acting on the vehiclein-motion at first. The second step is to determine the dy- 
namic axle loads by calculation according to data from the previous measurements and technical vehicle parameters. It is necessary to make higher number of weight and static axle load measurements to reach some statistical accuracy. This condition is valid also for braking measurements of vehicle deceleration. The static axle load measurement gives results enouncing the longitudinal position of the vehicle gravity center. But for the calculation of the dynamic axle loads it is necessary to know the vertical position of the vehicle gravity center (the height of the vehicle gravity center). It follows from the above that all those static weight measurements must be done before the dynamic braking measurements.

These time consuming methods were used because of higher value form the practical point of view. The transport company or transport operator cannot measure actual dynamic axle loads and this amount has no redeemable value for them. But it is possible to make a measurement of static axle loads on almost every loading or unloading place. And the combination of the actual static axle loads of the vehicle and the knowledge of its impact on the vehicle deceleration can lead to secure higher traffic safety.

According the theoretical knowledge in this field, the lowest vehicle gravity center and the equally at the static axle loads should secure the highest values of the vehicle deceleration.

\section{Data and Methods}

The methods used to determine the influence vehicle center of gravity on the braking characteristics were:

1. Loaded vehicle mass measurement - measurement of static axle loads

2. Loaded vehicle height of gravity center measurement - measurement of static axle load during different relative heights of axles

3. Braking deceleration measurements - measurement of vehicle deceleration during its full braking by measuring device - accelerometer

4. Calculation of the dynamic axle loads according to measured values and technical dimensions of the vehicle

The braking characteristics were measured on a twoaxle vehicle N1 Citroën Jumper Furgon 4-35 L4H3, which is the longest and highest version of this model line designed for cargo transportation. The weight of the empty vehicle with the driver was detected by the mobile scales. It was found that the front axle was $1560 \mathrm{~kg}$ while the rear was
$920 \mathrm{~kg}$, so the weight of the empty vehicle with the driver is $2480 \mathrm{~kg}$. By subtracting the empty vehicle weight from the maximum permissible vehicle weight, the highest possible payload can be obtained at $1020 \mathrm{~kg}$. In this way it was also easy to calculate:

- maximum front axle payload: $540 \mathrm{~kg}$;

- maximum rear axle payload: $1480 \mathrm{~kg}$.

\subsection{Load distribution diagram of Citroen Jumper $\mathrm{L} 4 \mathrm{H} 3$}

Based on maximum permissible load of both axles, on the information about maximum payload of the vehicle and on the dimensions of the used car for measuring, a load distribution diagram was drawn up. The black dot also shows all the loads mentioned above.

The area of correct positioning of the cargo in the diagram is bounded by the curve of maximum permissible front axle load, and in particular the maximum payload line, which may be higher depending on the drivers weight and the fuel level in fuel tank. In the case of any load distribution there are no axle load limits exceeded.

\subsection{Calculation of vehicles center of gravity height}

The amount of tipping moment, which changes the axle load during braking, depends on the braking deceleration and the center of gravity position and thus the center of gravity height [18-20]. It was therefore crucial to calculate the vehicles center of gravity height to obtain axle load data during braking $[21,22]$. This can also be determined by considering the weight on any of the axles on an inclined plane of known slope. Then the vehicles center of gravity height is calculated according to formula (1):

$$
h_{t}=\frac{m_{z 2} \cdot L-m \cdot L_{1}}{m \cdot \operatorname{tg} \alpha}+r_{s}
$$

where:

$\mathrm{h}_{t}$ - height of center of gravity [m]

$\mathrm{m}_{z 2}$ - vehicle mass in inclination per lower axle [kg]

$L$ - wheelbase [m]

$m$ - vehicle gross mass $[\mathrm{kg}]$

$L_{1}$ - distance of the higher axle from the center of gravity

in the horizontal plane [m]

$\alpha$ - angle between horizon and inclined plane $\left[{ }^{\circ}\right]$

$r_{s}-$ wheel radius [m] 


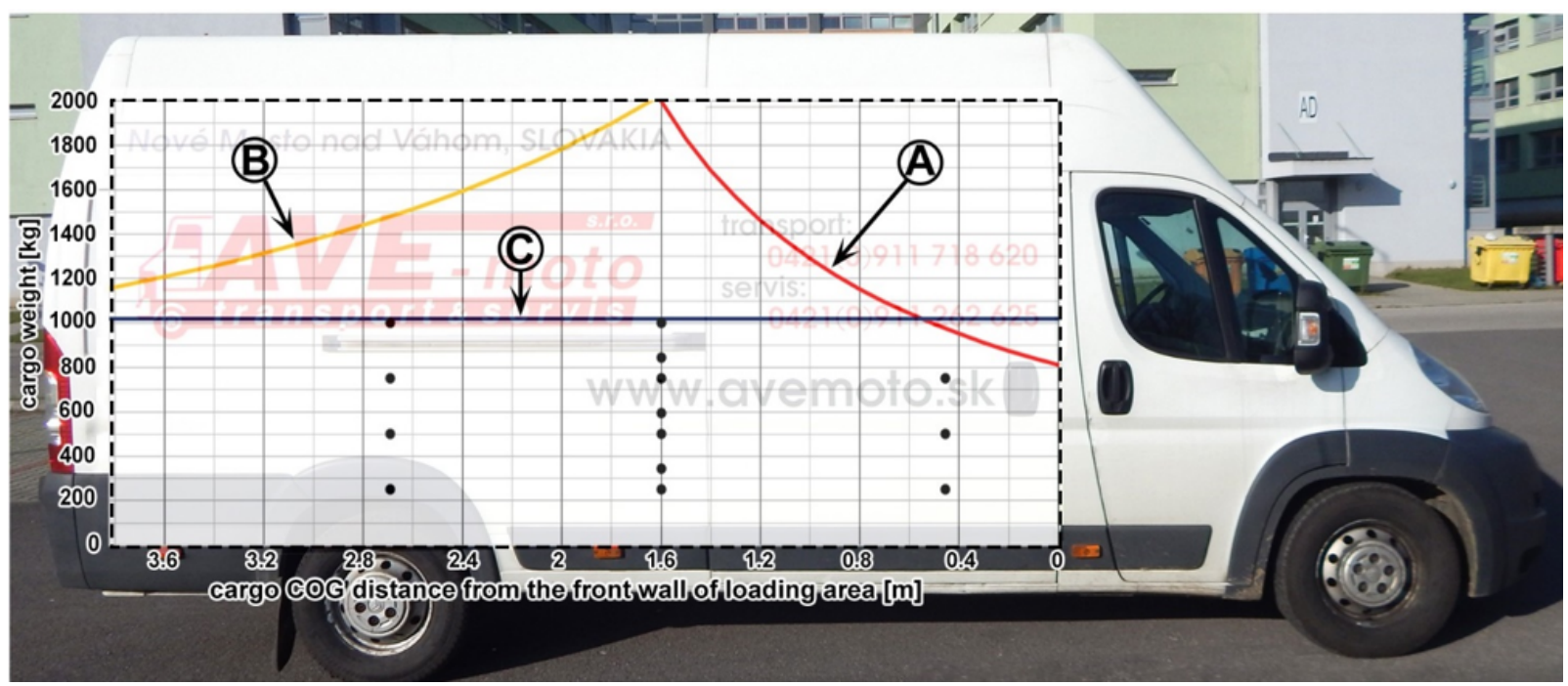

The Legend:

A - maximum permissible front axle load

$\mathrm{B}$ - maximum permissible rear axle load

$\mathrm{C}$ - maximum payload of the vehicle

Figure 1: Load distribution diagram of Citroen Jumper L4H3. Source: Authors

After inserting all known values into equation (1), the vehicles center of gravity is obtained (2):

$$
\begin{aligned}
h_{t} & =\frac{1600 \mathrm{~kg} \cdot 4035 \mathrm{~mm}-2480 \mathrm{~kg} \cdot 2538 \mathrm{~mm}}{2480 \mathrm{~kg} \cdot \mathrm{tg} 8,4^{\circ}} \\
& +355 \mathrm{~mm} \doteq 797 \mathrm{~mm}
\end{aligned}
$$

After the calculation it can be stated that an empty Citroën Jumper Furgon L4H3 with a driver has a center of gravity height of $797 \mathrm{~mm}$, which, given the location of the powertrain, the entire chassis and the floor of the loading area, may be sufficiently accurate.

\subsection{Calculation of axle loads during braking}

The braking tests of the vehicle were carried out with different load distribution with different weight but always with an initial speed of $75 \mathrm{kmph}$. The test results were automatically measured by a decelerometer, with measuring of the most important parameter - MFDD (mean fully developed deceleration), which is the best value characterizing the braking of the vehicle. To verify that the results were not affected by the low value of the operating force on the brake pedal, the magnitude of this force were recorded by a pedometer. Three pallet units filled with river stones with a total weight of $250 \mathrm{~kg}, 500 \mathrm{~kg}$ and $750 \mathrm{~kg}$ were used for the measurement. For the purpose of calculating the axle load change during braking, the height of the center of gravity was also estimated.
The cargo has been loaded on the loading area in the longitudinal plane in three different places. The front of the loading area, directly over the axis of the rear axle and at a place between them (see Figure 1). At each of these three locations, each of the three loading transport units was successively loaded and secured individually. This placement of the loading transport units gave 9 stowage options thus 9 different axle loads. A load of $1000 \mathrm{~kg}$ of cargo was achieved by using the yellow $250 \mathrm{~kg}$ pallet at the same time behind the blue $750 \mathrm{~kg}$ loading transport unit. Both pallets were secured in two places, so that their common center of gravity was above the rear axle and at the place between the front wall of the loading area and the rear axle.

To determine the impact of the height of center of gravity of the cargo on braking, it was also placed at different heights from the floor in addition to the longitudinal axis of the vehicle. All three pallet units were gradually loaded on five stacked pallets in the middle between the front wall of the loading area and the rear axle. The $1000 \mathrm{~kg}$ load was simulated by using the pallet with mass $750 \mathrm{~kg}$ loading unit over the pallet of $250 \mathrm{~kg}$.

With the value of the center of gravity height, the weight on the axles during braking may be calculated by deriving from equations (3) and (4). The only unknown remains the braking force, which can be calculated from equations (5) and (6). 


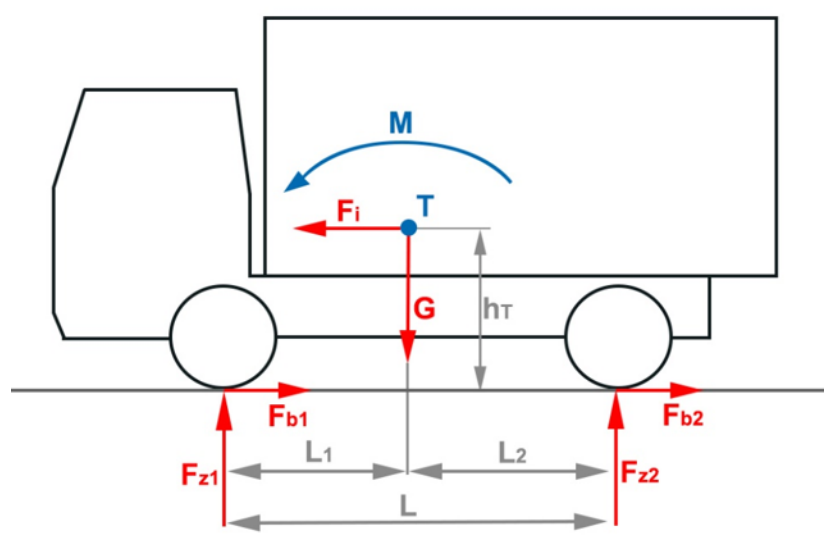

The Legend:

$\mathrm{F}_{i}$ - inertia force $[\mathrm{N}]$

$\mathrm{T}$ - center of gravity of the vehicle

$\mathrm{G}$ - gravity [N]

$\mathrm{M}$ - torque changing the axle load [N.m]

$\mathrm{h}_{T}$ - center of gravity height $[\mathrm{m}]$

$\mathrm{F}_{b 1}$ - front axle braking force [N]

$\mathrm{F}_{b 2}$ - rear axle braking force $[\mathrm{N}]$

$\mathrm{F}_{z 1}$ - front axle load [N]

$\mathrm{F}_{z 2}$ - rear axle load [N]

$\mathrm{L}_{1}$ - distance of front axle axis from center of gravity [m]

$\mathrm{L}_{2}$ - distance of rear axle axis from center of gravity [m]

$\mathrm{L}$ - wheelbase $[\mathrm{m}]$

Figure 2: The forces applied to the braked vehicle. Source: Authors

$$
\begin{gathered}
F_{z 1}=\frac{G \times L_{2}+F_{i} \times h_{t}}{L}[\mathrm{~N}] \\
F_{z 2}=\frac{G \times L_{1}-F_{i} \times h_{t}}{L}[\mathrm{~N}] \\
F_{b 1}=m_{c} \cdot b\left(\frac{L_{2}}{L}+\frac{h_{t}}{L} \cdot \frac{b}{g}\right)[\mathrm{N}] \\
F_{b 2}=m_{c} \cdot b\left(\frac{L_{1}}{L}-\frac{h_{t}}{L} \cdot \frac{b}{g}\right)[\mathrm{N}]
\end{gathered}
$$

Where:

$\mathrm{m}_{c}-$ vehicle gross mass $[\mathrm{kg}]$

$\mathrm{b}$ - braking deceleration $\left[\mathrm{m} \cdot \mathrm{s}^{-2}\right]$

$\mathrm{g}-$ acceleration of gravity $\left[\mathrm{m} \cdot \mathrm{s}^{-2}\right]$

\subsection{The cargo, its loading and securing}

Since during the tests the vehicle developed maximum braking deceleration, it had to be given to ensure a level playing field for each trio of braking tests, ruled out any slide of the cargo [23, 24]. Most critical was securing of $1000 \mathrm{~kg}$ load with a high center of gravity by using a combination of top-over lashing and spring lashing with three pcs of lashing straps ensure the cargo against sliding even at maximum braking deceleration [25-28].

When securing lighter cargo enough top-over lashing and direct diagonal lashing. The top-over lashing was the most important because by increasing the frictional force to the mat, it prevented the cargo from sliding in all directions [3, 16, 29-33].

\section{Results}

Since the cargo has been loaded in up to 15 different ways and also it was measured an empty vehicle, measured data from 16 different axle loads are available. In fact, up to three braking tests were performed at each particular load, which were then averaged to eliminate an accidental measurement deviation. MFDD size together with the stopping distance is compared in the following table (Table 1) with the position of the center of gravity of the cargo and the front axle load at rest and during braking that is determined by calculation. The calculated braking force also adds data.

From the weight difference in the table, its possible to see, how much mass is added to the front axle when braking. In the extreme case, when the $1000 \mathrm{~kg}$ cargo was loaded in height, a load of up to $638 \mathrm{~kg}$ was shifted from the rear axle.

\subsection{Influence of the cargo mass and cargo position on the floor on MFDD}

MFDD data from the first nine cases in which the load was loaded and secured directly to the floor of vehicle are graphically compared in the following figure (Figure 5).

From the graph it seems that MFDD size (deceleration size) depends on the weight of the cargo, but its size depends primarily on its distance from the front wall of the loading area. In particular, there is a visible change in the developed deceleration of a vehicle with a cargo of more than $250 \mathrm{~kg}$. The more the cargo is located from the front wall of the loading area, the more MFDD increases.

There is only a small difference between MFDD values depending on the mass of the cargo. However, an increasing trend of the MFDD can be seen as a function of increasing weight and distance of the cargo from the front 

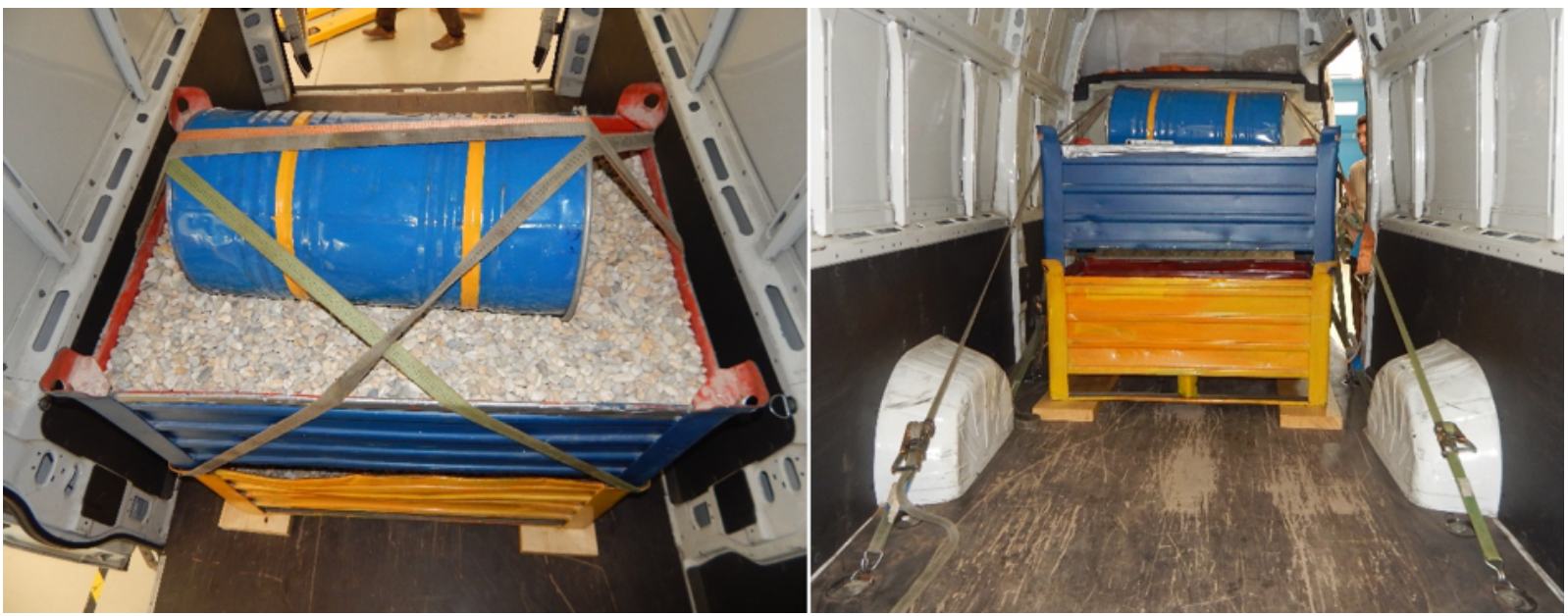

Figure 3: Securing of the $1000 \mathrm{~kg}$ load with high COG. Source: Authors

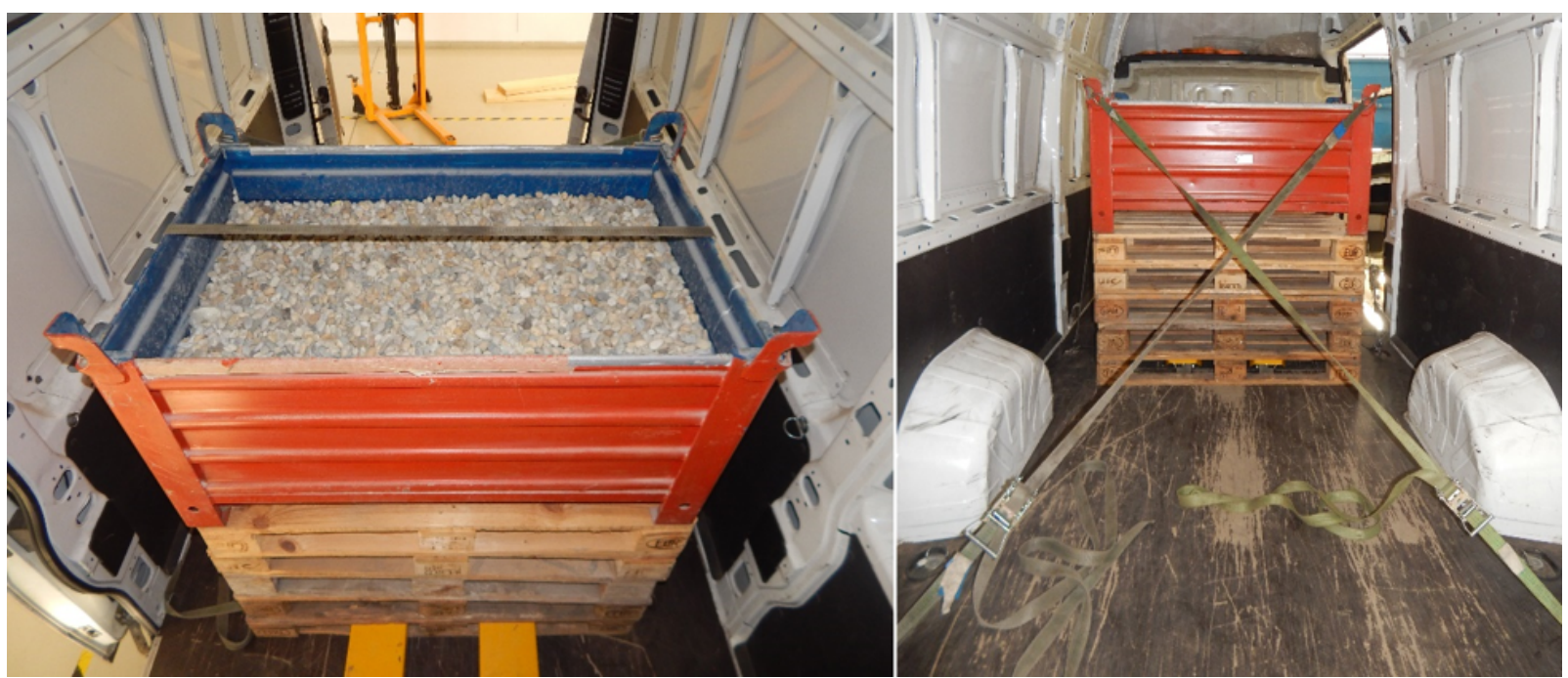

Figure 4: Securing of the $500 \mathrm{~kg}$ load with high COG. Source: Authors

wall of the loading area. The graph (Figure 5) shows that with a higher weight cargo, both better and worse braking deceleration results can be achieved than with a lighter cargo. The result depends mainly on the cargo location. It can therefore be assumed that when transporting heavier cargo, this difference will be more noticeable and this results will be reflected also in the stopping distance.

However, the above has not been confirmed by the results of the measurement of vehicle characteristics with only a $250 \mathrm{~kg}$ cargo. Since the increase in the distance of the cargo from the front wall of the loading area showed a slight increase and a further considerable decrease of MFDD, it is not possible to speak about dependence. That means, the position of the light cargo does not seem to affect the braking deceleration. A measurement error is also acceptable. But, the developed deceleration was definitely not low, and the cargo position at the front achieved the second highest value after the empty vehicle test values. Just an empty vehicle achieved almost the highest deceleration result. The higher value was developed only by a vehicle with a $1000 \mathrm{~kg}$ cargo placed directly above the rear axle. Conversely, the worst MFDD was achieved with 750 $\mathrm{kg}$ of cargo at the front of the loading area [34, 35].

After a complete analysis of the graph can be said that the braking deceleration decreases at a low mass of the cargo with an increase in distance from front wall of the loading surface $[36,37]$. Furthermore a heavier load affects braking deceleration more by its position on the loading surface than by the weight itself. Thus, placing the cargo further from the front wall increases the MFDD values, which may also exceed the values measured with an empty vehicle [38-40]. 
Table 1: Measured and calculated data recorded during braking tests Source: Authors

\begin{tabular}{ccccccccc}
\hline $\begin{array}{c}\text { Weight of the } \\
\text { Cargo [kg] }\end{array}$ & $\begin{array}{c}\text { Total Gross } \\
\text { Mass [kg] }\end{array}$ & $\begin{array}{c}\text { LL } \\
{[\mathbf{m m}]^{(2)}}\end{array}$ & $\begin{array}{c}\text { COG Height of } \\
\text { the Cargo }[\mathrm{mm}]\end{array}$ & $\begin{array}{c}\text { MFDD } \\
{\left[\mathbf{m} \cdot \mathbf{s}^{-2}\right]}\end{array}$ & $\begin{array}{c}\text { Stopping } \\
\text { distance }[\mathbf{m}]\end{array}$ & $\begin{array}{c}\mathbf{m}_{1}{ }^{(3)} \\
{[\mathbf{k g}]}\end{array}$ & $\begin{array}{c}\mathbf{m}_{1}^{\prime(4)} \\
{[\mathbf{k g}]}\end{array}$ & $\begin{array}{c}\mathbf{F}_{b}{ }^{(5)} \\
{[\mathbf{N}]}\end{array}$ \\
\hline $\mathbf{2 5 0}$ & $\mathbf{2 7 3 0}$ & 455 & 210 & 7,95 & 30,32 & 1698 & 2118 & 21704 \\
& & 1600 & 210 & 7,96 & 29,64 & 1628 & 2060 & 21731 \\
& & 2690 & 210 & 7,91 & 30,12 & 1560 & 1991 & 21594 \\
\hline $\mathbf{5 0 0}$ & $\mathbf{2 9 8 0}$ & 455 & 266 & 7,83 & 30,80 & 1837 & 2289 & 23343 \\
& & 1600 & 266 & 7,89 & 30,52 & 1695 & 2161 & 23502 \\
& & 2690 & 266 & 8,00 & 30,00 & 1560 & 2039 & 23830 \\
\hline $\mathbf{7 5 0}$ & $\mathbf{3 2 3 0}$ & 455 & 325 & 7,81 & 31,05 & 1975 & 2468 & 25226 \\
& & 1600 & 325 & 7,88 & 30,51 & 1763 & 2270 & 25463 \\
& & 2690 & 325 & 8,01 & 29,75 & 1560 & 2083 & 25883 \\
\hline $\mathbf{1 0 0 0}$ & $\mathbf{3 4 8 0}$ & 1600 & 296 & 7,90 & 30,05 & 1830 & 2376 & 27480 \\
& & 2690 & 296 & 8,05 & 29,33 & 1560 & 2102 & 28014 \\
& & 1600 & 760 & 7,89 & 30,28 & 1830 & 2468 & 27457 \\
\hline $\mathbf{8 4 3}^{(1)}$ & $\mathbf{3 3 2 3}$ & 1600 & 951 & 7,79 & 31,12 & 1856 & 2460 & 25886 \\
\hline $\mathbf{5 9 3}^{(1)}$ & $\mathbf{3 0 7 3}$ & 1600 & 869 & 7,83 & 30,26 & 1788 & 2320 & 24072 \\
\hline $\mathbf{3 4 3}{ }^{(1)}$ & $\mathbf{2 8 2 3}$ & 1600 & 758 & 7,87 & 29,63 & 1721 & 2182 & 22208 \\
\hline Empty & $\mathbf{2 4 8 0}$ & - & - & 8,02 & 29,28 & 1560 & 1961 & 19898 \\
Vehicle & & & & & & & & \\
\hline
\end{tabular}

(1) weight of cargo including weight of 5 pallets $(93 \mathrm{~kg})$

(2) $\mathrm{L}_{L}$ - distance of the center of gravity of the cargo from the front wall of the loading area [mm]

(3) $\mathrm{m}_{1}$ - mass of the vehicle stationary on the front axle [kg]

(4) $\mathrm{m}_{1}^{\prime}$ - front axle mass during braking $[\mathrm{kg}]$

(5) $\mathrm{F}_{b}$ - vehicle braking force $[\mathrm{N}]$

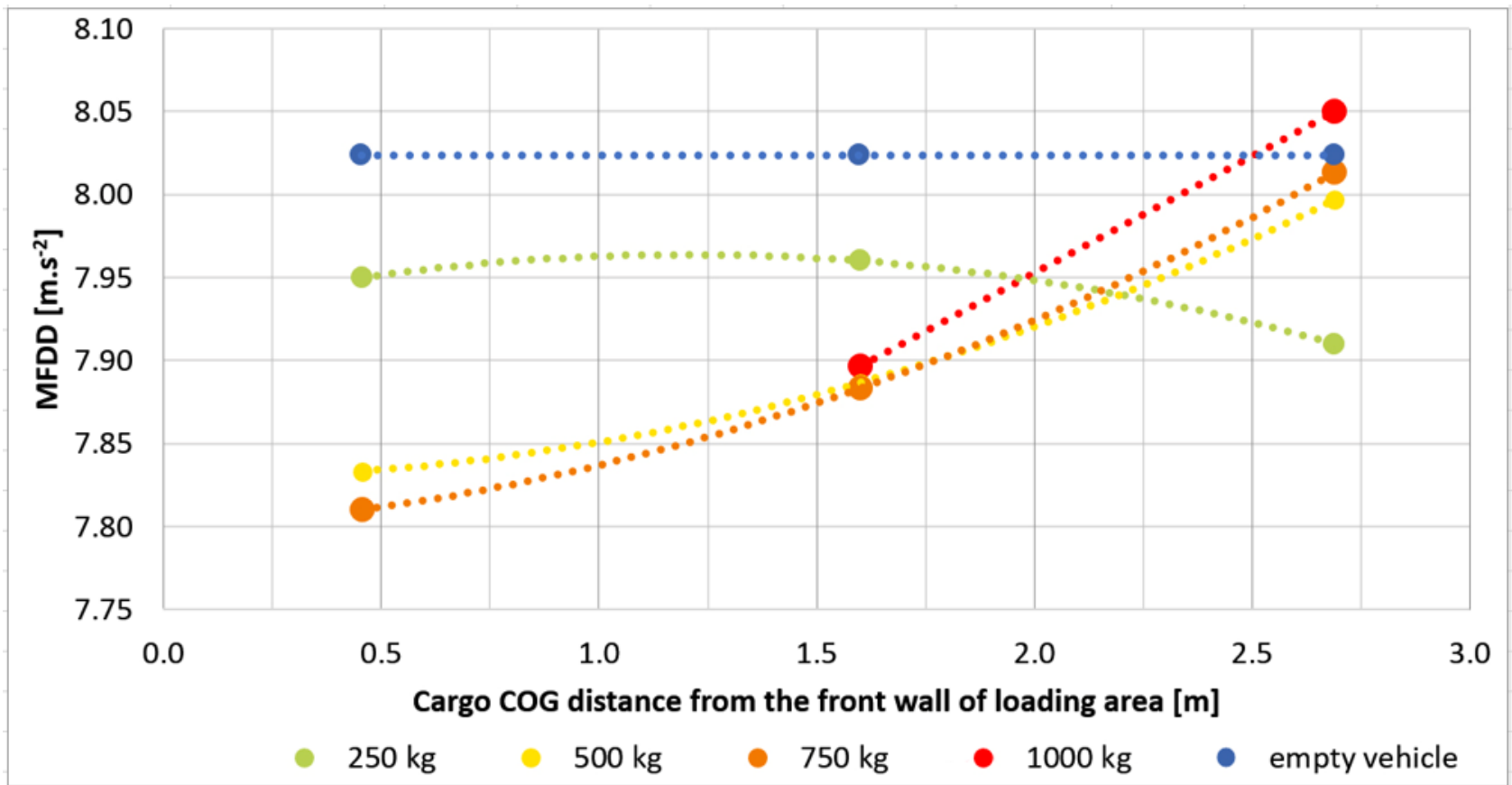

Figure 5: Influence of the cargo mass and its position on the floor on MFDD Source: Authors 


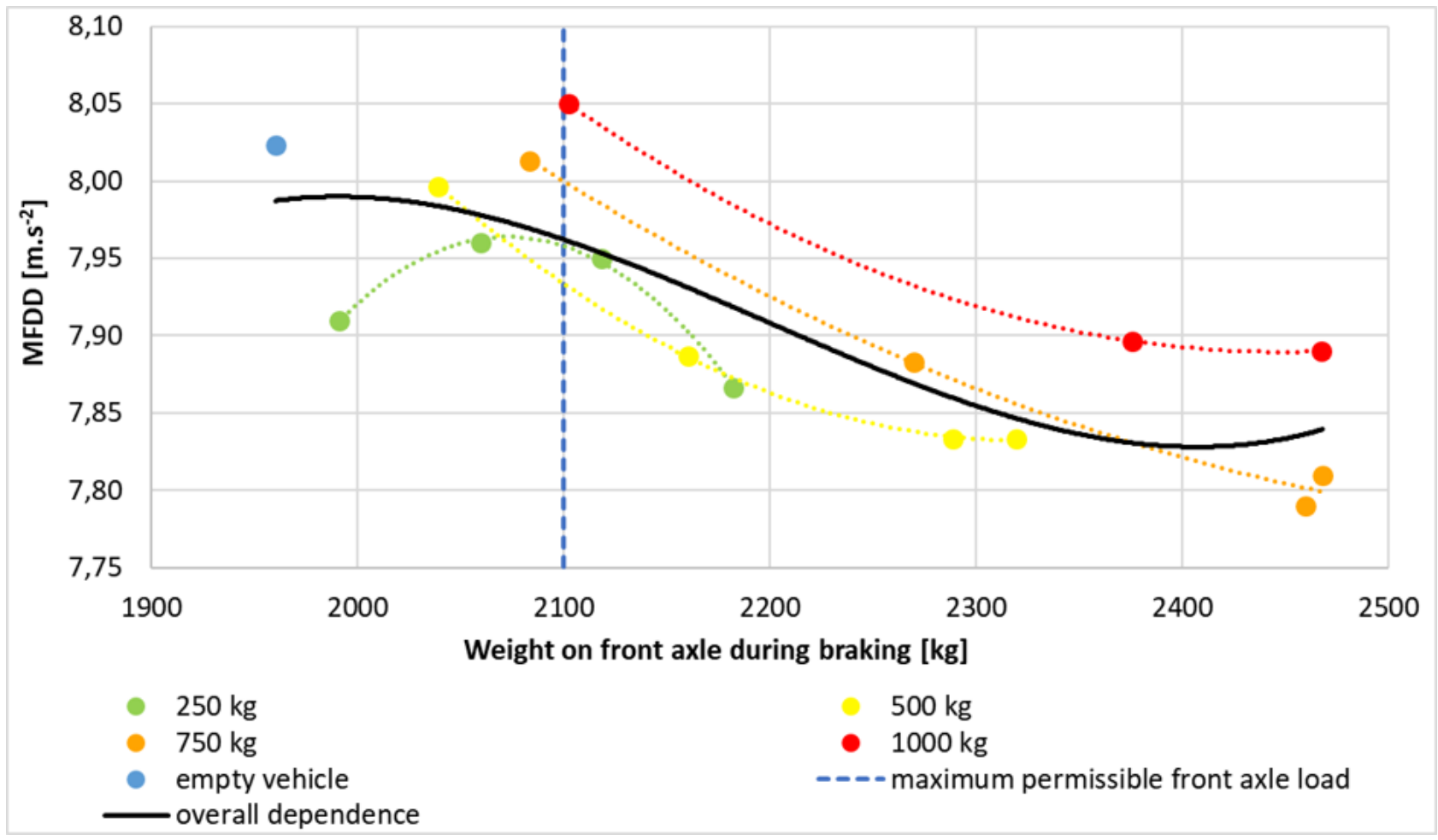

Figure 6: Impact of front axle load during braking on MFDD Source: Authors

\subsection{Effect of load during braking}

If we want to objectively assess the impact of cargo stored in height, the position of the center of gravity in the horizontal and vertical direction must be replaced by one variable. Such a variable can be for example weight on each axle during braking, because this variable depends mainly on the position and weight of the load.

The development of different load distribution values is indicated by the trend line with the polynomial function of the third degree. It can be seen that the increase in the load transmitted by the front axle during braking reduces the MFDD value. All these values are higher in the left part of the graph and lower in the right part. The point on the $\mathrm{x}$-axis that split them is approximately $2125 \mathrm{~kg}$. This value is actually identical to the maximum permissible front axle load $(2100 \mathrm{~kg})$. It is questionable whether this phenomenon is caused by an under-dimensioned braking system or by a friction coefficient between the tire and the road, which makes the tire unable to pass on higher loads.

Depending on the carried cargo dimensions, an even greater overload of the front axle can be achieved, for example by shifting the cargo forward. During the tests with mass of stacked cargo $1000 \mathrm{~kg}$, there was the option to move the cargo more about 1 meter closer to the front wall of the loading area, while respecting the maximum permis- sible front axle load. This would be achieved during braking even greater overloading of the front axle estimated $2700 \mathrm{~kg}$ (depending on the achieved MFDD).

\subsection{Effect of payload utilization rate}

The following two graphs illustrate the importance of utilizing the payload that the axles are able to transfer within their permissible load and its impact on MFDD.

According to Figure 6 a higher payload utilization rate is reflected in lower MFDD values achieved during braking. Since the utilization rate of the maximum payload of the front axle is related to the absolute load during braking, this graph provides the same conclusions as the previous one. For this reason, it can be concluded that shifting of the cargo closer to the front wall of the For heavier vehicles of category N2, this seemingly small change in MFDD $\left(0.26 \mathrm{~m} \cdot \mathrm{s}^{-2}\right)$ between the highest and the lowest payload utilization rate results in a much more noticeable difference (more than $1 \mathrm{~m} \cdot \mathrm{s}^{-2}$ ).

In order to understand the graph in Figure 8, it is necessary to see the context of Figure 6. There the MFDD reached the higher values, the lower the payload rate was transferred by the front axle. Less than $0 \%$ utilization rate can be achieved practically only by the placing cargo behind 


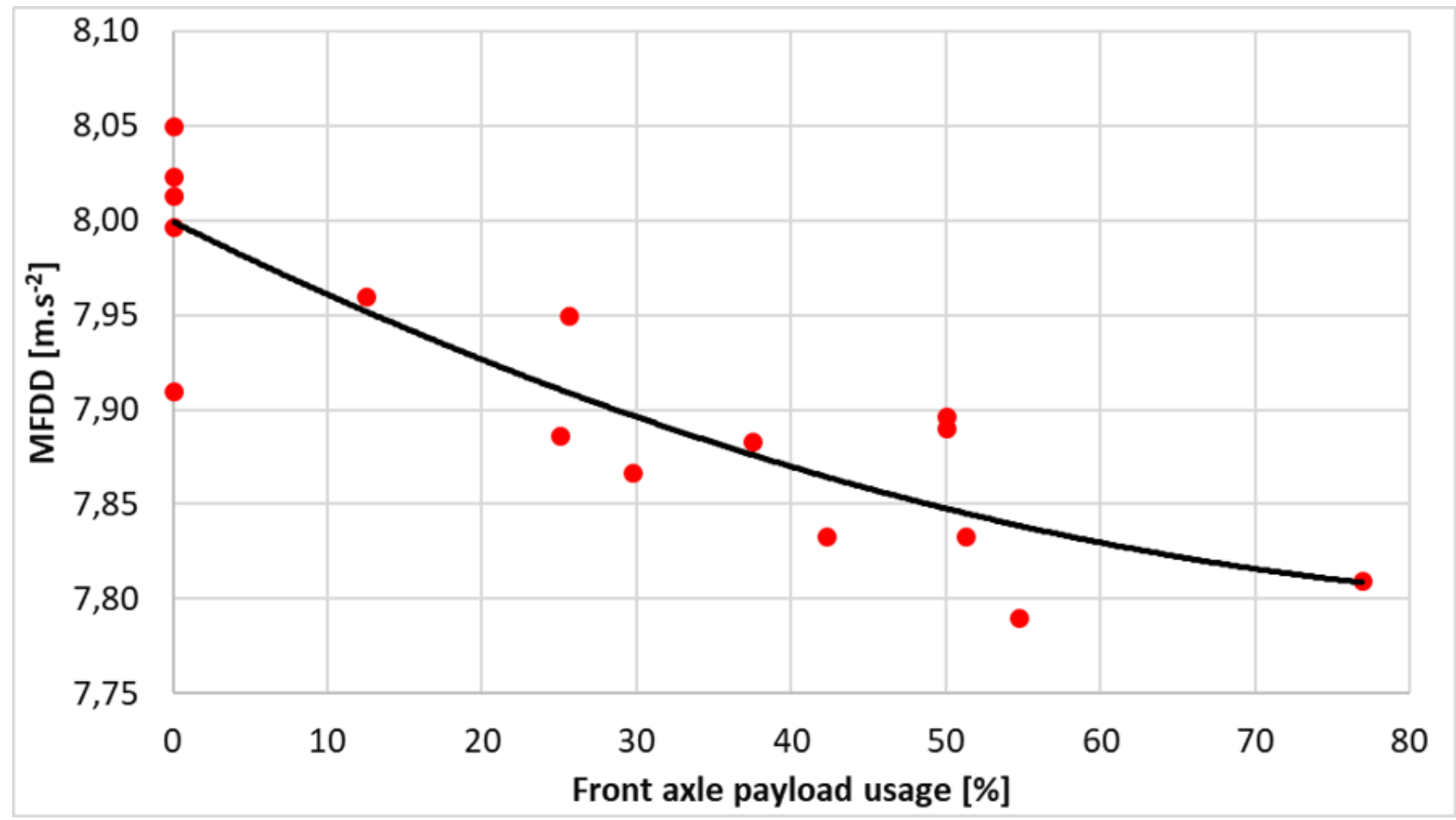

Figure 7: Dependence of the payload utilization rate of front axle on the MFDD Source: Authors

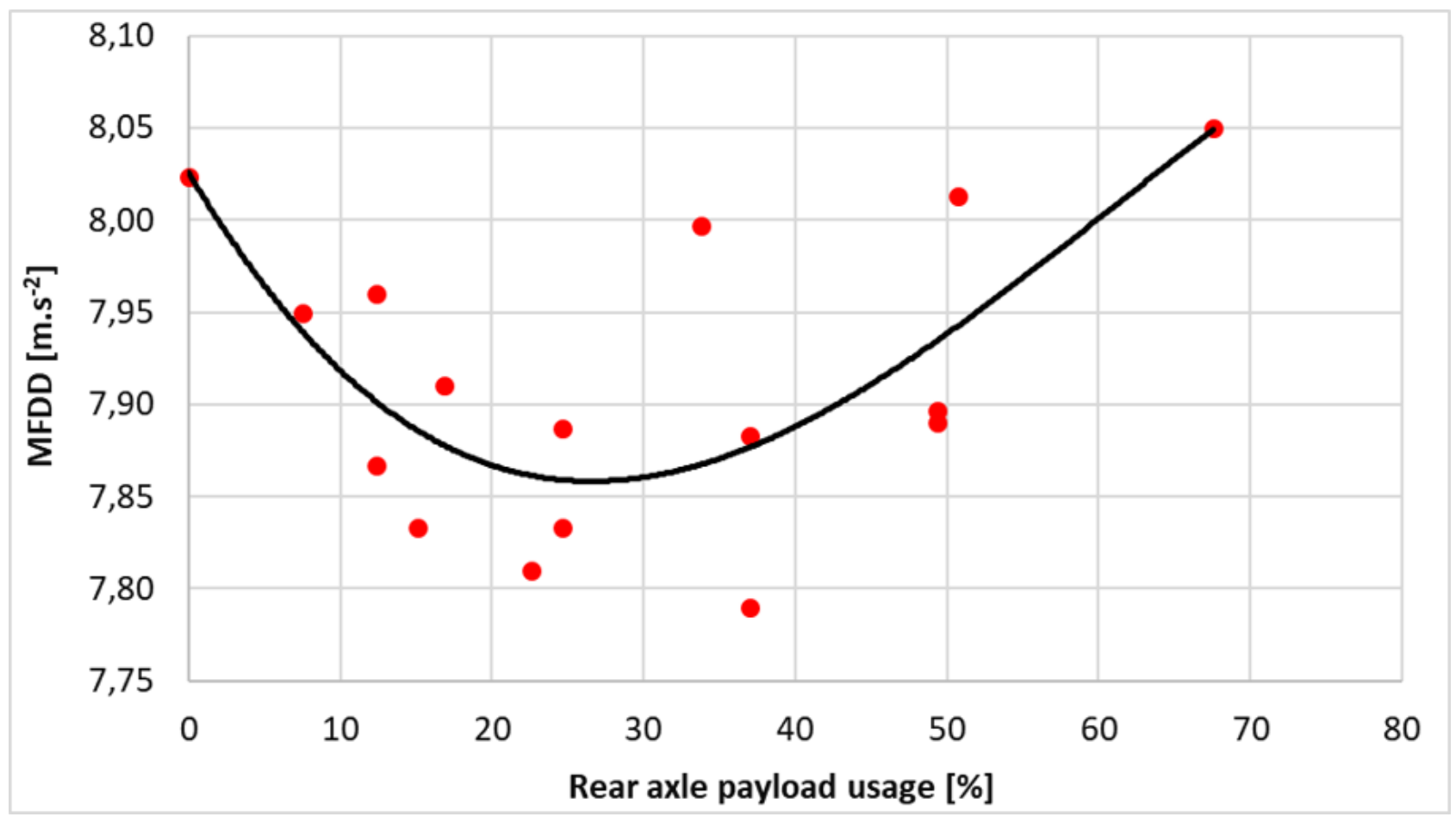

Figure 8: Dependence of the payload utilization rate of rear axle on the MFDD Source: Authors 


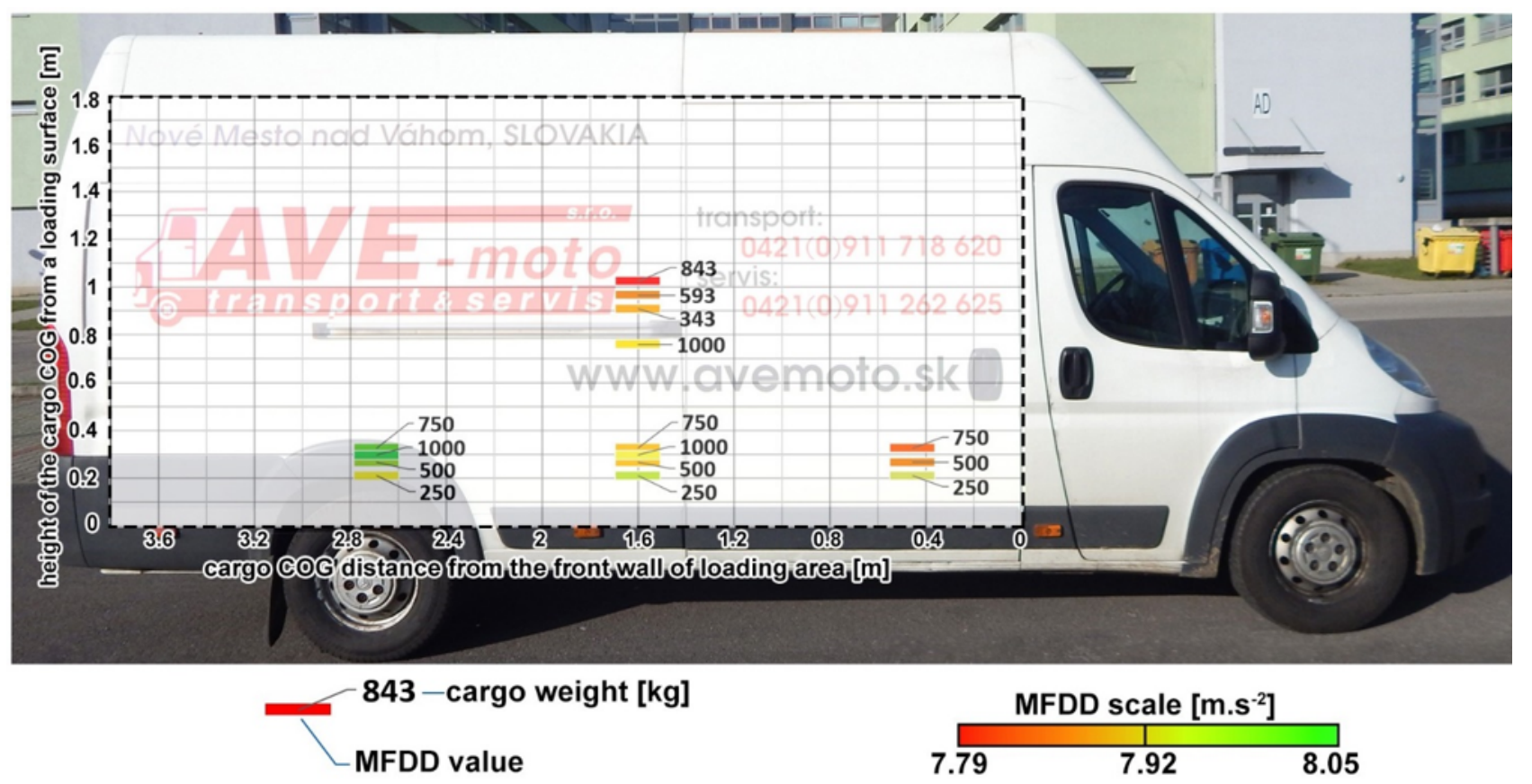

Figure 9: Influence of cargo location and its weight on braking deceleration Source: Authors

the rear axle, thereby relieving the front axle and loading the rear axle. This would move the cargo from the front wall of the loading area and at the same time increase the value of the MFDD.

A higher payload utilization rate of rear axle of tested vehicle and in the given measurement conditions without relieving the front axle is not possible. The reason is the placing of the heavier cargo between the front wall of the loading area and the rear axle would exceed the maximum permissible gross mass of the tested vehicle $(3500 \mathrm{~kg})$.

\section{Discussion}

Previous graphs have provided important insights into how the cargo effects on the vehicle braking. However, it is difficult to tell where exactly the cargo needs to be loaded on loading area to rich the optimal braking characteristics [41, 42]. Such knowledge can be found in the following picture.

The position of the cargo is here (Figure 9) precisely scaled relative to the $\mathrm{x}$-axis - the distance of the center of gravity of the cargo from the front wall and with respect to the y-axis - the height of the center of gravity of the cargo from the floor of the loading area. The color scale shows the MFDD value can be achieved by the van with such the load distribution. To the right of each center of gravity (numbers close to colored cells) is the mass of the load.

It can be seen in the figure that lower weight of cargo does not greatly affect vehicle braking, although they cause a decrease in MFDD compared to zero load. Thus, the horizontal position of the lighter cargo does not have a clear effect on the vehicle braking [43]. The heavier cargo already shows the influence of its mass and its position. Placing a heavier cargo in the front of the loading area worsens braking. Conversely, the heavier goods loaded in the rear part of the loading area improve MFDD values and thus reduce the stopping distance. It is important to ensure that the cargo is distributed correctly in relation to the height of the center of gravity from the floor of the loading area. In fact, the high center of gravity of the cargo will easily cause the lower MFDD values, as can be seen in the color range of goods of different mass with high center of gravity, loaded between the front wall of the loading area and the rear axle.

With an empty vehicle, almost the best MFDD values is achieved. With the increasing weight of the cargo in front part of the vehicle, the value of MFDD decreases. After exceeding a certain cargo weight (between 250 and $500 \mathrm{~kg}$ ), the front axle is overloaded during braking and the MFDD further decreases. This value may be higher only if the cargo is located near the rear axle, causing the front axle will transmit lower load. If the cargo is over $500 \mathrm{~kg}$ and placed directly above the rear axle, the total center of grav- 
ity of the cargo will be shifted more to the rear axle than to the front axle. For this reason, when loading cargo, it is important to look not only at braking characteristics as well as other aspects of driving dynamics. For example, in a situation where $1000 \mathrm{~kg}$ of cargo were loaded, the load was split in a 45/55 ratio (front/rear axle).

The used methods to determine the dynamic axle loads are numerous and time consuming. The accuracy of the given results is decreasing with increasing the difficulty of the methods, numbers of them and used measuring devices. Results introduced in this work have a scientific value but they are more useable in the operation of a transport company to achieve the highest safety of the process. We could reach the results with higher scientific accuracy by direct measuring of the dynamic axle loads but it is not possible to use in praxis. So higher redeemable value for praxis has this used one but more complicated combination of methods.

\section{Conclusion}

The results confirm expectations based on theoretical knowledge of the solving problem, that with the increasing height of the center of gravity (at the same cargo mass) the braking deceleration decreases (Figure 9) and that the vehicle is able to reach higher values of the braking deceleration within smaller axle load differences (Figure 7 and 8) what can be introduced in the practical expression by cargo position on the loading area (Figure 9).

Based on the results of the measurements, it is recommended to loading heavy goods in N1 vehicles as low as possible and as close to the rear axle as possible. In some cases, the highest braking deceleration can be achieved even if the cargo center of gravity position is beyond the rear axle of the vehicle. However, the loss of directional stability when driving forward caused by a center of gravity closer to the rear axle than to the front could be problematic [44, 45].

In practice, it is sometimes very stressful, inconvenient and, due to the time pressure, complicated to loading the cargo further away from the front wall of the loading area. In this way of loading, the cargo must be secured in another way or use a larger number of the lashing strips. It should be noted that shifting of the cargo closer to the rear axle can shorten the stopping distance by up to 1.5 meters. At first glance, it seems to be a very short distance to the total stopping distance of approximately 30 meters. However, such a shortening can prevent damage event, a road accident, injuries or loss of life. It should be noted that the
N1 vehicle weighing $3500 \mathrm{~kg}$, will reduce the driving speed by $18 \mathrm{kmph}$ over a distance of 1.5 meters.

\section{References}

[1] Yu Z, Wang J. Simultaneous Estimation of Vehicle's Center of Gravity and Inertial Parameters Based on Ackermann's Steering Geometry. Journal of Dynamic Systems, Measurement, and Control. 2017;139(3).

[2] Morales J, Martinez J, Mandow A, Seron J, Garcia-Cerezo A. Static Tip-Over Stability Analysis for a Robotic Vehicle With a SingleAxle Trailer on Slopes Based on Altered Supporting Polygons. IEEE/ASME Transactions on Mechatronics. 2013;18(2):697-705.

[3] Vrabel J, Jagelcak J, Zamecnik J, Caban J. Influence of Emergency Braking on Changes of the Axle Load of Vehicles Transporting Solid Bulk Substrates. Procedia Engineering. 2017;187:89-99.

[4] Marczuk A, Caban J, SAVINYKH P, TURUBANOV N, ZYRYANOV D. Maintenance research of a horizontal ribbon mixer. Eksploatacja i Niezawodnosc - Maintenance and Reliability. 2016;19(1):121125.

[5] Deng Z. Online Estimation for Vehicle Center of Gravity Height Based on Unscented Kalman Filter. 4th International conference on transportation information and safety. 2017.

[6] Stopka O, Kampf R. Determining the most suitable layout of space for the loading units' handling in the maritime port. Transport. 2016;33(1):280-290.

[7] Koziol M, Figlus T. Failure Progress of 3D Reinforced GFRP Laminate during Static Bending, Evaluated by Means of Acoustic Emission and Vibrations Analysis. Materials. 2015;8(12):87518767.

[8] Sree Ram S, Raja P, Sreedaran K. Optimization of rollover stability for a three-wheeler vehicle. Advances in Manufacturing. 2017;5(3):279-288.

[9] Kulikowski K., Kamiński Z. Methods for improving the dynamic properties of the air braking systems of low-speed agricultural trailers. The Archives of Automotive Engineering - Archiwum Motoryzacji. 2019;84(2):5-22. doi:10.14669/AM.VOL84.ART1.

[10] Fundowicz P. About Estimation of Height of 90 the Center of Gravity of Van-type Automobile. Proceedings of the 20th international scietific conference transport means 2016. 2016. p. 203 - 206.

[11] Nogowczyk P., Pałka A., Szczęśniak G. The influence of mass parameters of the body on active safety of a fire engine in terms of the selection of chassis. The Archives of Automotive Engineering - Archiwum Motoryzacji. 2018;82(4):87-98. doi:10.14669/AM.VOL82.ART7.

[12] Zitrický V. Possibilities of development of railway sidings in the Slovak Republic. Proceedings of the international conference on traflc and transport engineering. 2016. p. $454-461$.

[13] Chen M, Yin G, Zhang N. Joint Estimation of Center of Gravity Position and Mass for the Front and Rear Independently Driven Electric Vehicle with Payload in the Start Stage. Proceedings of the 35th Chinese control conference. 2016. p. 1932 - 1937.

[14] Staszak J, Ludwinek K, Gawęck Z, Kurkiewicz J, Bekier T, Jaśkiewicz M. Utilization of Permanent Magnet Synchronous Motors in Industrial Robots. International Conference on Information and Digital Technologies. 2015. p. 342-347. 
[15] Figlus, T. and Liscak, S., Assessment of the vibroactivity level of Sl engines in stationary and non-stationary operating conditions, Journal of Vibroengineering, vol. 16 (3), May 2014, pp. 1349-1359.

[16] Skrúcaný, T., Vrábel, J., Kendra, M. and Kažimír, P., Impact of Cargo Distribution on the Vehicle Flatback on Braking Distance in Road Freight Transport, in proc. Matec Web of Conferences, 18th International scietific conference - LOGI 2017, vol: 134, DOI: 10.1051/matecconf/201713400054.

[17] Mokričková, L. and Rievaj, V., Position of the centre of gravity and driveability of the vehicle, Logi : scientific journal on transport and logistics. v. 7, 2016, pp. 108-115.

[18] Hac, A., Fulk, D. and Chen, H., Stability and control considerations of vehicle-trailer combination, SAE International Journal of Passenger Cars - Electronic and Electrical Systems Vol: 1, 2009, pp: $925-937$.

[19] Moreno, G., Manenti, V. and Nicolazzi L. et al., Rollover of long combination vehicles: Effect of overweight, Mechanisms and Machine Science, Vol: 54, 2017, pp: 497 - 505.

[20] Moreno, G., Nicolazzi, L. and Vieira R., et al., Three-dimensional analysis of the rollover risk of heavy vehicles using Davies method in proc. 14th International Federation for the Promotion of Mechanism and Machine Science World Congress, 2015, DOI: 10.6567/IFToMM.14TH.WC.PS4.006.

[21] Jagelčák, J., Kubasáková, I. Load distribution in general purpose maritime container and the analysis of load distribution on extendable semitrailer container chassis carrying different types of containers. In: Nase more, Vol. 61 (5-6), 2014, pp. 106-116, 2014, ISSN 0469-6255.

[22] Consolidated TEXT: 31996L0053 - EN - 26.05.2015 [Internet]. Eur-lex.europa.eu. 2020 [cited 12 February 2020]. Available from: http://eur-lex.europa.eu/legal-content/EN/TXT/HTML/?uri=CE LEX:01996L0053-20150526\&from=SK

[23] Caban, J. et al. The research on ageing of glycol - based brake fluids of vehicles in operation. In: Advacnec in Science and Technology - Research Journal. Vol: 10, pp: 9 - 16, 2016 DOI: $10.12913 / 22998624 / 65113$.

[24] Gigan, L. Improvement in the brake disc design for heavy vehicles by parametric evaluation. In: Proceedings of the institution of mechanical engineers part D - journal of automobile angineering. Vol: 231, pp: 1989 - 2004, 2017, DOI: $10.1177 / 0954407016688421$.

[25] Guney, B., Mutlu, I., Gayretli, A. Investigation of braking performance of NiCrBSi coated brake discs by flame spraying. In: Journal of the Balkan Tribological Association, vol: 22, 2016, pp: $887-903$.

[26] Haugland, O. Car stopping distance on a tabletop. In: Physics teacher, Vol: 51, 2013, pp: $268-268$.

[27] Ondruš, J., Hockicko P. Braking deceleration measurement using the video analysis of motions by Sw tracker. In: Transport and Telecommunication, Vol: 16, 2015 pp: 127 - 137.

[28] Jammes, Y. et al. Emergency braking is affected by the use of cruise control. In: Traffic Injury Prevention, Vol: 18, pp: 636 - 641, 2017, DOI: 10.1080/15389588.2016.1274978.

[29] Vrábel, J. et al. Influence of Emergency Braking on Changes of the Axle Load of Vehicles Transporting Solid Bulk Substrates. In: Transbaltica 2017: Transportation and technology, Vol: 187, pp: 89 - 99, 2017, DOI: 10.1016/j.proeng.2017.04.354.

[30] Lagel, M. et al. Automotive brake pads made with a bioresin matrix. In: Industrial Crops and Products, Vol: 85, pp: 372 - 381, 2016, DOI: 10.1016/j.indcrop.2015.12.090.
[31] Lazeet, D. et al. Analysis of truck braking system in terms of construction and operation. In: Acta technica napocensis series - aplied mathematics mechanics and engineering, Vol: 59, 2016, pp:209 - 218.

[32] Li, E. et al. Influences of initial braking velocity and passenger capacity on Mean Fully Developed Deceleration. In: Mechanical engineering an materials, Vol: 281, 2013, pp: 201. DOI: 10.4028/www.scientific.net/AMM.281.201.

[33] Li, W. et al. Vehicle Braking Efficiency On-Line Monitoring and Evaluation with MFDD. In: Advances designs and researches for manufacturing, PTS 1-3, Vol: 605 - 607, pp_968, 2013 DOI: 10.4028/www.scientiAMR.605-607.968.

[34] Metz, L. Friction on Polished vs. Newly Re-Rocked Oil-and-Chip Roadway Surfaces. In: SAE international journal of passenger cars - mechanical systems. Vol: 9, pp: 541 - 545, 2016, DOI: 10.4271/2016-01-1568.

[35] Mikušová, M. Crash avoidance systems and collision safety devices for vehicle occupants. In: Dynamics of civil engineering and transport structures and wind engineering. Vol: 107, 2017, DOI: 10.1051/matecconf/201710700024.

[36] Oyetubo, A., Afolabi, O., Ohida, M. Analysis of Road Traffic Safety in Minna Niger State, Nigeria. In: Logistics \& Sustainable Transport, 9(1), pp. 23-38. 2018, DOI:10.2478/jlst-2018-0003.

[37] Paraskevadakis, D. et al. The impact of transport infrastructure projects on sustainable development within a major logistics gateway in North West England. In: Logistics \& Sustainable Transport, 7(1), pp. 28-40. 2016, DOI:10.1515/jlst-2016-0003.

[38] Rievaj, V. et al. Tire inflation pressure influence on a vehicle stopping distances. In: International Journal of Traffic and Transportation Engineering. Vol: 2 pp: 9 - 13, 2013, Doi:10.5923/j.ijtte.20130202.01.

[39] Rievaj, V., Mokričková, Synák, F. Temperature of the brakes and the braking force In: Transport and communications : scientific journal.. - Vol. 5, no. 1, pp: 16 - 16, 2017, ISSN 1339-5130.

[40] Selig, M. et al. The influence of tyre contact patch and on the stopping distance of automotive vehicles. In: 25th International Congress on Condition Monitoring and Diagnostic Engineering (COMADEM), Vol: 364, 2012, DOI: 10.1088/17426596/364/1/012014.

[41] Timur, M., Kuscu, H., Toylan H. Design and manufacture of automated controlled test machine detecting braking characteristic of brake lining in vehicles. In: Proceedings of the institution of mechanical engineers part C - Journal of mechanical engineering science. Vol: 231, pp: 3318 - 3329, 2017, DOI: 10.1177/0954406216645128.

[42] Zamzamzadeh, M. et al. Dynamic simulation of brake pedal force effect on heavy vehicle braking distance under wet road conditions. In: International Journal of Automotive and Mechanical Engineering, Vol: 13, pp: 3555 - 3563, 2016, DOI: 10.15282/ijame.13.3.2016.2.0292.

[43] Zhang, L. et al. All-Wheel Braking Force Allocation During a Braking-in-Turn Maneuver for Vehicles With the Brake-by-Wire System Considering Braking Efficiency and Stability. In: IEFE Transactions on Vehicular Technology, Vol: 265, pp: 4752 - 4767, 2016, DOI: 10.1007/978-3-319-24577-5_17.

[44] Zhao, L. Vehicle Braking Stability Analysis in Turn Condition. In: Machines Design and manufacturing Engineering III, pp: $604-$ 607, llos, A., Al-Hadithi, M., 1992. Driver behaviour during onset of amber at signalised junctions. Traffic Engineering and Control 33 (5), 2014,p: 312-317. 
[45] Ondruš, J.; Kolla, E. The impact of ABS system on the braking characteristics of the specified motorcycle on the dry road surface In: International Automotive Conference (KONMOT 2018). ISSN 1757-8981. IOP Conference Series: Materials Science and Engineering, Volume 421, Issue 2, 2018, Article number 022024 